\title{
Fast Growth of Keep (An Online Fitness APP) During COVID-19 Pandemic
}

\author{
Xupeng $\mathrm{Lu}^{1, *}$ \\ ${ }^{1}$ Muma College of Business, University of South Florida, Tampa, Florida, US, 33612 \\ *Corresponding author. Email:1787076955@qq.com
}

\begin{abstract}
A global pandemic broke out in 2020. While the traditional business model has suffered a severe blow, some new business models have begun to appear on the stage of history, for example, Keep (An online fitness app) completed a rapid accumulation and conversion of user, and standed out among home-fitness industry. This article regards the pandemic period as the research background, takes Keep as the research case, collects official statistical data and interview records through second-research methods. Based on the 4P theory, this study also explains how Keep uses its own advantages (Big Data) to quickly locate customer needs, adjust product strategies, and maintain a high user retention rate. Finally, the article summarizes Keep's "Consumer Needs and Products\&Channels" loop model, clarifies the new relationship between these two sides in big data era, and provides new ideas for product development in Internet industry.
\end{abstract}

Keywords : COVID-19 pandemic, modern marketing, big data, home fitness, Keep

\section{INTRODUCTION}

The COVID-19 pandemic has dealt a serious blow to the global economy. Many industries have been destroyed and many physical companies are facing bankruptcy. However, for a small number of industries, this pandemic is seen as a good opportunity, such as e-commerce giant Amazon and various remote office software, which have grown rapidly in this special period. And, in China, a fitness app named "Keep" also stood out during this crisis. According to relevant statistics, in the second quarter of 2020, Keep's monthly active users exceeded 20 million, far surpassing the former industry leader YueDongQuan, which has only 9 million.[8] And as of 2021, Keep has completed 7 rounds of financing, the number of daily active users exceeds 6 million, and the total number of users is about 300 million.[5]

So how did Keep become the dark horse in home fitness industry and how did it grow such rapidly during the pandemic? This article will discuss the changes in the fitness market during the pandemic firstly, and then, based on 4P theory, explains the marketing strategy adopted by Keep from multiple perspectives and gives the answer.
4P theory: Product, Price, Place, Promotion which is first proposed by Professor Jerry McCarthy. Since Keep is a modern Internet company, there will be some overlaps between these four dimensions, so this article does not give strict boundaries between them. And in order to explain the success of Keep and fit the background better, the factor "technology" has also been taken into consideration.

\section{CHANGES IN THE MARKET DURING THE PANDEMIC}

From 2019 to 2020, "home fitness" has become a hot-word in startup companies and investments, and online fitness market grows at a high speed, especially in the outbreak of the pandemic. In 2019, the scale of China's home fitness market reached 28.15 billion RMB, with a compound annual growth rate of $35.5 \%$ in 5 years, and it is expected to reach 40.4 billion RMB in 2021. Similarly, in the US, the share price of fitness technology company "Peloton" reached 44.38 billion $\mathrm{RMB}$ in 2020, increasing more than $550 \%$ compared with 2019. Moreover, according to the "2018-2020 Alibaba Fitness Equipment Sales Statistics", the sales of fitness equipment generally have two peaks each year, in February-March and November-December, and under the pandemic situation, the peak value from 
February to March 2020 has clearly exceeded the average level.[6]

For consumers, this pandemic increased their awareness of health and due to social restrictions, home fitness has become a popular choice.[2] McKinsey pointed out in the "China Consumer Report 2021": After the pandemic, home fitness users have increased by $23 \%$, of which $60 \%$ intend to continue the online way. After trying online fitness, the preferences of some consumers have changed, consumers increasingly like and rely on this flexible and price-friendly fitness way.

\section{ANALYZE KEEP'S STRATEGY BY USING 4P+T THEORY}

\subsection{Price}

As an Internet industry, Keep has the inherent advantages of low cost and light assets compared to traditional industries. For example, one of the main profits of the traditional fitness industry comes from private coaching courses, while Keep turned paid courses into free when it launched online, thereby quickly accumulated user traffic. And with more people are willing to spend money on online knowledge, Keep has also developed private course. However, when compared with competitors, Keep's private course does not have advantages at price. The price of courses in the whole online industry is pretty low, normally from 16.9 $\mathrm{RMB}$ to $99 \mathrm{RMB}$, and there is no room for a price reduction. Therefore, the only way for Keep is to improve the quality and form of online courses and to find new business models while maintaining price unchanged.

\subsection{Product \& Technology}

\subsubsection{Prudent product positioning to be a supplier of home fitness solutions}

"It is often more effective to brake at the right time than blindly accelerate." As a rapidly growing and expanding Internet company, Keep has identified its future direction during the pandemic. Keep has been focusing on the home fitness scene since 2019, and the emergence of the pandemic has confirmed its direction.[3] Vice President Dong.L said: "Keep's core business has always been around the needs of core users. Our core users are users based on family, so we regard "home" as the main fitness scene. We will not do diving, skiing and other similar sports, because it is not what our core users really want to experience on Keep. "

\subsubsection{Build a new generation of sports brand with the help of Big Data}

Keep has accumulated a large amount of business experience and user data, relying on the existing online platform and big data system, so it can know the user's status and what customers want more accurately. Keep divides the user's exercise process into four parts: $\mathrm{Be}$ aware of exercise; Purchase necessary equipment; Experiencing content services and social interaction during the exercise; Able to see the data results after exercise. However, for traditional sports brands, whether it is sportswear brands such as Nike, Adidas or sports equipment brands such as Bowflex, CAP Barbell, they are mainly at the level of awareness and equipment sale, as for whether users will really exercise after purchasing the product, they have no idea.[1] Therefore, Keep spent a lot of time focusing on building the latter two links. It provides solutions during the exercise and presents the exercise results on the App. These results will further push the user to strengthen their exercise, and, according to the result, Keep can recommend more suitable sports for its users. Over time, these data will form a closed loop of user experience in the form of AI, and users will be willing to pay for it when they get a good experience.

\subsubsection{Course innovation, occupying the live streaming channel}

When all competitors still use pre-recorded training videos as course content, Keep launched live courses in June 2020. Yue.Z, head of Keep's live streaming business, said: "From the perspective of technological change, the advent of the $5 \mathrm{G}$ era will not only change people's lifestyles, but also make tremendous changes in the entire TMT(Technology, Media, Telecom) industry. In the future, video carriers in each field will be gradually converted to live streaming form, such as: e-commerce, online education, variety shows, and fitness."[9] From the perspective of consumer habits, the post-00s and post-10s are a group of people who have grown up with iPhone and iPad. They are very familiar with live streaming. They take online classes, follow celebrities through live shows, and when they grow up and have fitness needs, they will also choose the online way.

Compared with pre-recorded training course, online courses have a huge advantage, that is, "atmosphere". Keep online class has set up different forms of interactive functions. Every user who enters the streaming room can exercise with the coach and communicate by sending barrage to get a strong sense of participation. And, during the online class, the coach will make real-time adjustments to the training rhythm based on the user's feedback - if the course is generally difficult for users to reply, the coach will reduce the 
difficulty, and vice versa. This two-way output method is more in line with normal fitness sense and is more "user-oriented".

At the same time, Keep does not ignore the importance of coaches. As the "medium" for the platform to create a deep connection with users, coaches can help the platform reach users in a more comprehensive manner and increase user's loyalty. Keep has been working hard to recruit excellent live coaches, including many professional trainers who were unemployed due to the pandemic. In order to ensure the quality of the courses and user experience, Keep has established a long-term online training plan for coaches.[7] In addition to traditional fitness expertise, online coaches also need to practice camera performance, community content and fans management. Keep has also configured a cooperative team for coaches to take charge of all-around packaging and promotion. In return, these coaches will become Keep's "second competitiveness".

\subsubsection{Establish social circle and User growth system to increase retention rate}

Except spending great efforts on product innovation and promotion to continuously attract new users, Keep maintained the retention rate of existing users cautiously. For an explosive Internet company, the ability to quickly accumulate a large number of users is indeed an exciting thing, but in the early days of the online fitness industry, there was a serious problem of homogeneity between Keep and its competitors, and this problem leads to a very low switching costs for users, so what Keep did is to cultivate users' habits and increase their exit costs.

What Keep did first is a social drive. By building a social circle, Keep makes users invest more time and emotions, and be more reluctant to leave the platform. And, relying on UGC and PGC (User-generated Content and Professionally-generated Content), Keep creates an online community, establishes a coach-fan system, and promotes users to share fitness knowledge and experience through various topics. These high-quality content attract users to like, share, and comment. When people start to interact frequently, the relationship chain is established and the exit cost is increasing. In order to encourage users to share more, Keep has done a lot of experience optimization around posting. One is to link up with Weibo hotspots to provide users with content directions. The other is to add filters and stickers to the image content to reduce the psychological burden of some users who dare not share because of being unconfident.

In addition, Keep has established a complete user growth system, including a total of 20 levels, and each level corresponds to a different privilege.[4] Through gamification, users can witness their own growth. Every time they complete a milestone, they will get a badge. The higher the level, the rarer the privileges they get, which increases the fun of training and satisfy user's little vanity. Keep's user growth system has three characteristics: First, slowly increased threshold: the initial level is relatively easy to obtain, the first level requires $800 \mathrm{EXP}$, which can be gotten by only training 3-4 times, and such setting reduces the difficulty of entry. Second, timely rewards: when the user completes a certain training, Keep will immediately remind him to gain growth points and upgrade levels, and after each upgrade, Keep will generate honor cards to prompt the user to share and deepen their perception of rewards. Third, visible rewards: Keep displays the privileges that can be obtained at each level, allowing users to know their exercise direction and keeping their desire of exploring.

\subsection{Promotion\&Place}

Cooperate with celebrities and e-commerce
platforms

In 2019, the market size of China's live streaming e-commerce industry reached 443.75 billion RMB, an increase of 308.34 billion yuan from 2018, a year-on-year increase of $227.7 \%$, and the sudden outbreak of COVID-19 pandemic has also reinforced such growth. Keep, as a dark horse in online fitness industry, got onboard this fast train, it gave full play to the influence of celebrities. On November 18, 2020, Keep invited Nana.O, a famous young star with perfect body figure, to hold an e-commerce live streaming on TikTok. During the streaming, Keep encouraged Nana to try different fitness equipment and to express her real feeling, such format increased the sense of reality. This live streaming achieved unprecedented success, with a total of 4.55 million viewers, setting a record of single-live-streaming in the TikTok sports segment.

And in the 2020 Double Eleven, Keep used the same strategy. First, it used the celebrity effect to attract a lot of traffic, then gave free lottery to increase customer retention time, and finally, it used powerful CTA (Buy it, take care of health everyday, self-discipline gives freedom, etc.) to continuously stimulate consumer demands and transform those demands to buying behaviors. On that day, Keep's smart spinning bikes, widened yoga mats, yoga wheel won the most sales in each category. Especially, the transaction amount of smart spinning bike $\mathrm{C} 1$ has exceeded 10 million RMB. This spinning bike is bound with Keep software, consumers can get paid courses about bike exercise at a very low price after purchasing, and their exercise data will be recorded and analyzed by Keep. In such a way, Keep completed the process of "attracting-acquiring-retaining" quickly, and accumulated many new users. 


\section{CONCLUSION}

summarizes the "Consumer Needs and

This article uses the "4P+T" theory to study the logic of Keep's rapid growth during the epidemic, and

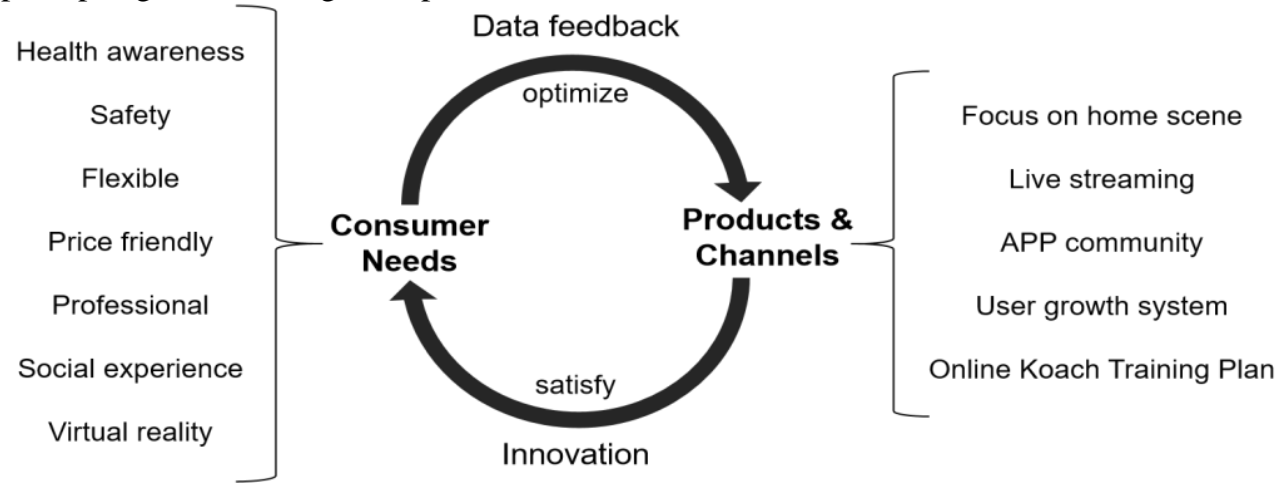

Figure 1 "Consumer Needs and Products\&Channels" Loop Model

The model shows that Keep relying on its advanced data system can keenly perceive changes in customer needs and quickly make product adjustments, forming a positive feedback relationship that promotes circulation.

From the perspective of customer needs, there are three levels. Firstly, the pandemic has led to an increase in people's health awareness and safety needs, so home fitness which reduces outdoor exposure has become the first level of needs; secondly, when people become familiar with this fitness method, consumers have the second level of needs for the basic nature of the product, such as quality (professional), price (price-friendly) and user experience (flexible); finally, when the basic needs are met, consumers will pursue personal satisfaction and sociality, this is the third level of demand.

From the perspective of product, Keep meets the first-level needs of consumers by "focus on home scene"; meets the second-level needs through setting a lower course price and Online Koach Training Plan; and meets the third-level needs through Live Streaming, APP community and User growth system. In addition, Keep connects its sports equipment with the app, completing the real-time data collection and a faster data feedback. These innovations meet the constantly updated needs of consumers, also bring a higher industry entry threshold and customer retention rates.

In fact, this Loop Model is not uncommon, but it circulates faster through the support of data system, and Keep has captured this. Now, Keep has changed the business model of the entire industry and is far ahead.

\section{REFERENCES}

[1] Xing, W., 2019. Research on the Development Strategy of Sports Fitness App Keep under the Background of "Internet +". Master. University of YanShan.

[2] Zhang, S. and Zhu, J., 2020. Research on the business model development strategy of home fitness companies in the post-pandemic era-taking Keep as an example. Master. Business College of Shandong Normal University.

[3] Zhang, X., Ji, Y. and Tang, Q., 2020. On brand building strategy of sports APP from consumption scenario construction -- take the "Keep" as an example. School of Journalism \& Communication, Hebei Institution of Communication.

[4] Xu, M., 2019. Making great efforts to content, Keep can Keep. Commercial Classic Case Library, p.96.

[5] 2021. In 6 years, with 300 million users and a \$2 billion valuation, how did Keep make it?. [online] Available

at: $<$ https://baijiahao.baidu.com/s?id=1688916810970 $262141 \& w f r=$ spider $\&$ for $=p c>$ [Accessed 6 August 2021].

[6] 2021. Home fitness, home's "self-discipline" business. [online] Available at: <https://baijiahao.baidu.com/s?id=1693751761732 059112\&wfr=spider\&for=pc $>$ [Accessed 6 August 2021].

[7] 2021. Keep live coaching becomes the new favorite of users, can fitness live streaming create another Jiaqi Li ? . [online] Available at: <https://baijiahao.baidu.com/s?id=1684324250596 $732104 \& w f r=$ spider $\&$ for $=p c>$ [Accessed 5 August 2021].

[8] 2021. Keep operating strategy, gain 170 million users in 4 years!. [online] Available at: <https://www.sohu.com/a/322648884_403902> [Accessed 6 August 2021].

[9] 2021. Keep's growth secret: the logic behind 200 million users and 1 billion sales. [online] Available at: 〈https://www.sohu.com/a/434301957_458789> [Accessed 6 August 2021]. 